\title{
Restructuring citrus endophytic diversity through potential indigenous endophytes could eliminate huanglongbing pathogen Candidatus Liberibacter asiaticus
}

\section{Shahzad Munir}

Yunnan Agricultural University

\section{Yongmei Li}

Yunnan Agricultural University

Pengfei He

Yunnan Agricultural University

Pengbo He

Yunnan Agricultural University

Pengjie He

Yunnan Agricultural University

Wenyan Cui

Yunnan Agricultural University

Yixin Wu

Yunnan Agricultural University

Xingyu Li

Yunnan Agricultural University

Qi Li

Yunnan Agricultural University

\section{Xiaobing Hua}

National and Local Engineering research center

Chongjun Zhao

National and Local Engineering Research Center

\section{Sixiang Zhang}

Binchuan institute of inspecting and detecting food and medicines

\section{Yangsu Xiong}

Binchuan Institute of inspecting and detecting food and medicines

\section{Wenbiao Wang}

Binchuan institute of inspecting and detecting food and medicines

\section{Kexian Zong}

Binchuan institute of detecting and inspecting food and medicines 


\section{Yongchao Yang}

Yuxi Academy of Agriculture Science

\section{Shaocong Yang}

Yuxi Academy of Agriculture Science

\section{Chan Mo}

Yuxi Academy of Agriculture Science

\section{Heming Wen}

Binchuan Institute of inspecting and detecting food and medicines

\section{Samantha C. Karunarathna}

Kunming Institute of Botany Chinese Academy of Sciences

\section{Steve L. Stephenso.n ( $\nabla$ slsteph@uark.edu )}

University of Arkansas Fayetteville https://orcid.org/0000-0002-9207-8037

\section{Yueqiu He}

Yunnan Agricultural University

\section{Research}

Keywords: Citrus, Bacillus subtilis, Endophytes, Pathogen, Restructuring, Microbiomes, Resistance genes

Posted Date: September 29th, 2020

DOI: https://doi.org/10.21203/rs.3.rs-74822/v1

License: (c) (i) This work is licensed under a Creative Commons Attribution 4.0 International License. Read Full License 


\section{Abstract \\ Background}

Huanglongbing (HLB) is a major botanical pandemic of citrus crops caused by Candidatus Liberibacter asiaticus (Clas). It is important to understand the different mechanisms involved in interaction of pathogen with plants to develop novel management strategy against HLB. However, until now there has been no control strategy to manage this disease in vitro and on large scale in citrus grove. We found that, indigenous endophyte Bacillus subtilis L1-21, a patented strain isolated from healthy citrus tree, may have the potential to reduce the impact of pathogen through restructuring of core endophytes.

\section{Results}

A novel half-leaf method was developed to test the efficacy of $B$. subtilis L1-21 against Clas. Concentration of $B$. subtilis L1-21 at $10^{4} \mathrm{cfu} \mathrm{ml}^{-1}$ resulted in a 1000-fold reduction in Clas copy densities per gram of leaf midrib $\left(10^{7}\right.$ to $\left.10^{4}\right)$ by $4 \mathrm{~d}$ after treatment. With endophytes, where HLB incidence was reduced to $<3 \%$ and Clas copy density was reduced from $10^{9}$ to $10^{4}$ pathogen $\mathrm{g}^{-1}$ of diseased leaf midrib. We found that 16 of 93 tree samples became Clas-free and functional pathways and pathogen resistance genes were regulated in diseased citrus trees after treatment.

\section{Conclusions}

This is the first large-scale study using an indigenous endophyte and shows its potential utility in sustainable disease management through strengthening the citrus microbiome.

\section{Introduction}

Huanglongbing (HLB), which is a major and uncontrollable disease of citrus trees resulting in significant yield losses [1], is caused by the phloem limited a-proteobacteria 'Candidatus Liberibacter asiaticus' (Clas), 'Ca. Liberibacter africanus', 'Ca. Liberibacter americanus'[2] and 'Ca. Liberibacter caribbeanus [3]. The nutrient-deficient bacterium, Clas may cause imbalances in host metabolism due to consumption of host nutrients[4]. The main vector of Clas is the Asian citrus psyllid (ACP), Diaphorina citri and understanding the mechanisms involved in pathogen-plant interaction is essential for the development of novel HLB management strategies[5, 6]. Approaches to control HLB include screening for small molecule inhibitors[7], combinations of stock and scion[8], graft-based chemotherapy[9, 10] and transgenic technology[11, 12]; however, none of these methods provides successful and effective disease management.

In citrus biocontrol programmes, plant defense mechanisms may be modulated by microbes to maintain long term colonization inside the host and eliminate effects of the Clas pathogen[13], but effects of 
disease development on microbe communities are unclear[14-16]. For example, disease progression may negatively affect microbe community structure[17]. Biocontrol of plant pathogens has yielded effective results using bacteria under laboratory conditions[18-20] and moderate effects under field conditions[21], but the potential of indigenous bacteria as economically useful biocontrol agents of plant pathogens has not been investigated. This approach may be used to manage citrus disease caused by phloem-limited a-proteobacteria[2], because there is evidence for negative effects on pathogen titers of Clas of changes in microbe population dynamics during HLB disease progression[22-24].

Plant diseases lead to perturbations of the host microbiome[25], so it is important to understand associated effects and the role of key bacteria on productivity. Thus, the aim of this study was to quantify effects of regular applications of indigenous endophytes (Bacillus subtilis) isolated from healthy citrus trees to diseased trees on Clas pathogen reduction and analyse pathways for pathogen resistance to introduced endophytes. We found the pathogen was successfully eliminated from diseased citrus trees since the introduction of endophytes using our novel half-leaf method, alongside other management tools.

\section{Results}

\section{Bacillus subtilis suppression of Clas in the laboratory}

We used indigenous endophyte Bacillus subtilis L1-21 against Clas in the leaf midrib by means of citrus half-leaf method (Fig. 1a, b) maintained under room temperature in Eppendorf tube. Copy density of Clas in leaf material was reduced by $5 \mathrm{~d}$ after treatment with the endophyte at $10^{4}$ and $10^{6} \mathrm{cfu} \mathrm{ml}-1$ (Fig. 1c); similarly, the antibiotics used in this experiment also reduced Clas copy density (Fig. 1d). Subsequent dilutions of the endophyte validated the results, confirming that Clas copy density inside the citrus leaf midrib was reduced by a single application of the endophyte.

To further confirm the efficacy of the endophyte against Clas, we used half-leaf method to test for pathogen copy density in one half of the leaf present in Petri dish treated with a single application of endophyte $\left(10^{4}\right.$ and $\left.10^{6} \mathrm{cfu} \mathrm{ml}^{-1}\right)$ खor penicillin antibiotic (as a positive control) and LB broth and water (as negative controls). Presence of the pathogen was confirmed using standard qPCR analysis (see Methods), and density (copies $\mathrm{g}^{-1}$ ) was calculated based on a standard curve generated by cloning 382 bp of a specific DNA fragment located in the ribosomal protein $(r p / j)$. Thus, the recombinant plasmid was designated as pMD18T-rp/J-HLB, and pathogen density was derived from treatment CT values of the standard curve [26]. qPCR amplification efficiency was $99 \%$ and melt curves confirmed specificity of the results. Initial copy densities of the pathogen in the leaf midribs treated with endophyte L1-21 $\left(10^{4}\right.$ and $10^{6} \mathrm{cfu} \mathrm{ml}^{-1}$ ), penicillin, LB and water were $1.12 \times 10^{7}, 1.23 \times 10^{6}, 4.71 \times 10^{5}, 2.38 \times 10^{5}$ and $1.51 \times 10^{6}$, respectively (Fig. 1e; Table S3). Application of the endophyte reduced Clas copy density in the leaf midribs 1000 -fold $\left(1.12 \times 10^{7}\right.$ to $\left.3.72 \times 10^{4}\right)$ and 100 -fold $\left(1.23 \times 10^{6}\right.$ to $\left.3.93 \times 10^{4}\right)$ by $4 \mathrm{~d}$ after a single treatment of $10^{4} \mathrm{cfu} \mathrm{ml}^{-1}$ and $10^{6} \mathrm{cfu} \mathrm{ml}^{-1}$ (Fig. 1g; Table S3) of the endophyte, respectively. Half-leaf method was also employed to check the pathogen reduction in individual leaves using top and bottom 
parts to confirm validation of results, and we showed that Clas could be reduced to more than $90 \%$ after 3-4 d (Table S4).

Prior to application of the endophyte, microbe endophyte density in the citrus leaves was $10^{5} \mathrm{cfu} \mathrm{g}^{-1}$; following a single treatment with endophytic strain L1-21, density increased to $10^{9} \mathrm{cfu} \mathrm{g}^{-1}$ (Fig. 1f, h). Application of penicillin initially decreased leaf midrib microbe density, but this effect subsided with time as endophyte density returned to pre-treatment levels. Endophyte density was unaffected by the LB and water treatments. Application of penicillin reduced Clas copy density in diseased citrus leaves 10 -fold $\left(4.71 \times 10^{5}\right.$ to $\left.1.64 \times 10^{4}\right)$, and there was no effect of LB or water controls by $4 \mathrm{~d}$ after treatment. These results clearly indicated that application of the endophytes reduced pathogen density in diseased citrus leaves.

\section{Efficacy of short-term fieldapplications of Bacillus subtilisagainst Clas}

In 2017-18, we tested the efficacy of $B$. subtilis L1-21 against Clas in two diseased citrus groves (100\% HLB prevalence) containing 16 and 4-year old citrus trees, respectively, based on the assumption that it may play an important role in the prevention of colonization and development of the pathogen in citrus trees. We treated the Clas-infected mandarin groves with contrasting applications of the endophyte, antibiotics and bio-fertilizers to determine the most effective management strategy (Fig. 2). HLB affected citrus grove was completely recovered after 6-7 months of successful treatment with indigenous endophyte (Fig. 2b, c). Antibiotics and bio-fertilizers were applied once at the start of the experiment, and endophytes were applied monthly, following leaf sampling to check densities of Clas and the endophyte. Prior to the start of the experiment, all citrus trees were tested for the total number of endophytes present inside each tree (Fig. 3a). B. subtilis L1-21 applied to the citrus trees spread to neighbouring, untreated trees (Fig. S1), so we tested microbe diversity of all citrus trees. Density of Clas and endophytes were measured monthly in leaf samples collected from each of the 162 citrus trees using conventional and nested PCR techniques (Fig. 3b-d). Health of leaves were improved following treatment with the endophyte for one year, where they changed from yellow to green, and we found negative effects of Clas on endophytic microbe community structure of citrus tree. Citrus trees were monitored monthly to assess visual disease symptoms, and following one year of monthly applications of $B$. subtilis L1-21, Clas density in the trees had been reduced. In the first quarter of experiment, the number of diseased trees had reduced to $<100$, where trees that had been characterised by yellowed and mottled leaves began to develop more robust shoots and leaves. The leaf density of citrus endophytes was initially reduced by the application of antibiotics, but later recovered to more than $10^{7} \mathrm{cfu} \mathrm{g}^{-1}$. By the second quarter of the experiment, the number of diseased trees had reduced to 69 , in which endophytes density was similarly increased; by the final quarter, the number of diseased citrus trees had been reduced to three and trees in the grove finally yielded fruit suitable for the commercial market. Thus, we confirmed that the endophyte B. subtilis L1-21 was the most effective control agent for the management of HLB and a reliable and cheap option for citrus growers worldwide. Strengthening citrus microbe diversity using an endophyte with diverse antagonistic activities through trunk injection and foliar spray application may elevate microbe diversity in diseased citrus trees to levels where Clas pathogen may more easily be controlled 
(Fig. 3e). Previously, we found the number of endophyte types was lower in diseased citrus trees, indicating that greater diversity of indigenous citrus endophytes may contribute to the control of Clas in diseased trees[24].

The copy density of Clas in leaf samples was reduced following 6 months of monthly treatments with $B$. subtilis L1-21 (Fig. 3f-g), confirming our hypothesis that indigenous citrus endophytes may reduce disease incidence in the field by $>95 \%$ (Fig. 4a-f). After a year of monthly applications of the endophyte, levels of $B$. subtilis L1-21 in citrus leaf material increased from $10^{3}$ to around $10^{9} \mathrm{cfu} \mathrm{g}^{-1}$ in most trees, showing that indigenous endophytes may represent a novel management strategy for the control of Clas in citrus plants. We have found similar effects of this endophyte on Clas in 2 other citrus groves in the study region and one each in the Maguan and Yongshan counties of Yunnan province (Fig. S2).

\section{Effects of long-term field applications of Bacillus subtilis on Clas}

To confirm the results from the one-year field experiments, we regularly treated diseased citrus groves, comprising 525 trees, with $B$. subtilis L1-21 in 2018-19; these regular applications reduced copy density of Clas in the citrus trees, so that the number of diseased trees was reduced. We selected 93 among the 525 trees, which represented three replicates of 31 trees, and found that after one year, regular applications of the endophyte had reduced the copy density of Clas from $10^{9}$ to $10^{4} \mathrm{~g}^{-1}$ of leaf midrib (Fig. 5a) (99\% control; Table 5). Clas copy density was very high in April 2018, but decreased within 3 months (Fig. 5b). In April 2019, we found 16 of the 93 diseased trees contained 100 copies of the pathogen $\mathrm{g}^{-1}$ of leaf material, while 39 contained $<100$ copies, representing $91.39 \%$ reduction in Clas pathogen copy density (Fig. 5c), and there was a decrease in the number of yellow leaves and shoots and an increase in the growth of new shoots (Fig. 5d). Our findings indicated that Clas pathogen density remained constant in around $25 \%$ of the citrus trees during endophyte treatment and was undetected in 16 of the diseased citrus trees in April 2019. Thus, Clas was successfully eliminated from the diseased citrus trees by $B$. subtilis L1-21.

\section{Analysing disease responsive genes}

Further, molecular mechanisms in citrus plants after introduction of endophytes to diseased trees resulted in the up-regulation of important genes responsible for pathogen/disease resistance, chaperone family protein and respiratory burst oxidase, and differentially expressed pathogen resistance genes involved in different pathways may improve plant defences during biotic stress. We selected the top 20 abundant KEGG pathways that were triggered following application of the endophyte (Fig. 6) on diseased trees. The major upregulated KEGG pathways included biosynthesis of secondary metabolites; plantpathogen interaction; and phenylpropanoid biosynthesis (padj<0.05) (Fig. 6a). In treatment of healthy citrus trees, major KEGG enrichment pathways comprised biosynthesis of secondary metabolites; metabolic pathways; biosynthesis of amino acids; and, phenylpropanoid biosynthesis (padj<0.05) (Fig. 6b). Upregulated pathogen resistance genes (in response to Clas) following endophyte application are pathogenesis-related 4 (PR4, Ciclev10029328m.g, Ciclev10029327m.g, Ciclev10029528m.g, 
Ciclev10029536m.g), disease resistance protein (CC-NBS-LRR class) family (Ciclev10030667m.g, Ciclev10024849m.g, Ciclev10024854m.g), chitin elicitor receptor kinase 1 (LYSM RLK1) (Ciclev10017678m.g), respiratory burst oxidase homologue D (RBOHD, Ciclev10027774m.g), mitogenactivated protein kinase 1 (MPK1, Ciclev10001531 m.g), Chaperone protein htpG family protein (HSP90.5, Ciclev10030743m.g), CRINKLY4 related 3 (CCR3, Ciclev10030732m.g), and phloem protein 2-A12 (Ciclev10021489m.g) (Fig. 6c; Table S6) and downregulated genes involved in pathogen resistance were heat shock protein 70 (Ciclev10027981m.g) and $17.6 \mathrm{kDa}$ class II heat shock protein (Ciclev10009756m.g), which are responsible for protein folding, indicating that the citrus trees treated with endophytes had previously contained Clas (Tables S7-S11). All read data are available in the SRA database (BioSample accession numbers SAMN15323747-SAMN15323758).

\section{Secondary metabolites expression}

Secondary metabolites play an important role in defense mechanism of citrus trees and other plants. Significant regulation was noted in the diseased citrus leaves after treatment with endophytes indicating the positive affect of these agents against Clas pathogen. Important genes related to secondary metabolites are related to metabolism of terpenoids and polyketides. Geranylgeranyl pyrophosphate synthase 1 (Ciclev10012067m.g), isopentenyl diphosphate isomerase 1 (Ciclev10012312m.g), hydroxymethylglutaryl-CoA synthase/HMG-CoA synthase/3-hydroxy-3-methylglutaryl coenzyme A synthase (Ciclev10020042m.g), and squalene synthase 1 (Ciclev10028537m.g) are the important genes upregulated in the diseased citrus trees after treatment with endophytes (padj<0.05). Lipoxygenase 2 (Ciclev10014199m.g) involved in jasmonic acid mediated response in leaves, aldehyde dehydrogenase 3F1 (Ciclev10025492m.g), and GroES-like zinc-binding dehydrogenase family protein (Ciclev10020620m.g) are responsible for metabolism of lipids. Other important genes related to regulation of secondary metabolites are peroxidase superfamily protein (Ciclev10021010m.g), branchedchain amino acid transaminase 2 (Ciclev10001429m.g), S-adenosyl-L-methionine-dependent methyltransferases superfamily protein (Ciclev10026344m.g, Ciclev10012561m.g), and aldehyde dehydrogenase 2C4 (Ciclev10010514m.g) (Table S7). The oxidative stress created by Clas pathogen inside citrus trees are detoxified through genes such as glutathione S-transferases (Ciclev10008944m.g, Ciclev10032702m.g, Ciclev10033001m.g, Ciclev10005808m.g, Ciclev10005812m.g), thus helping the citrus trees to showed tolerance to HLB. Two genes for phenylalanine ammonia-lyase (Ciclev10027913m.g, Ciclev10027912m.g) were upregulated when endophytes were applied to healthy citrus trees.

\section{Protein folding, chaperones, heat shock proteins}

The most important mechanism involved in the disease symptoms of huanglongbing are the down regulation of heat shock proteins, and product of these genes protect the protein folding and function during pathogen attack. The correct function is maintained in the phloem and leaves in the presence of these genes. We found that the genes responsible for protein folding are up regulated in the citrus trees treated with endophyte such as Chaperone DnaJ-domain superfamily protein (Ciclev10002683m.g, 
Ciclev10016883m.g, Ciclev10009810m.g), Chaperone protein htpg family protein (Ciclev10030743m.g), and Co-chaperone GrpE family protein (Ciclev10008685m.g). The fold change for all of these genes were more than 1 and the FDR ratio was (padj<0.05). Ubiquitin mediated protein degradation plays an important role in plant-pathogen interactions. There are 10 ubiquitin related genes regulated after endophyte treatment inside the citrus trees, 9 of them were up-regulated and 1 was down-regulated. The up-expressed genes are ubiquitin-conjugating enzyme/RWD-like protein (Ciclev10021040m.g), Plant UBox 15 (Ciclev10003715m.g), Transducin/WD40 repeat-like superfamily protein (Ciclev10007255m.g), senescence-associated E3 ubiquitin ligase 1 (Ciclev10030698m.g), Ubiquitin carboxyl-terminal hydrolase family protein (Ciclev10003568m.g), U-box domain-containing protein kinase family protein (Ciclev10018795m.g), plant U-box 29 (Ciclev10001380m.g), Rad23 UV excision repair protein family(Ciclev10011886m.g), and ubiquitin 4 (Ciclev10012291m.g). F-box/RNI-like superfamily protein (Ciclev10001527m.g) responsible for folding, sorting and degradation of proteins was downregulated (Table S8).

\section{Genes responsible for photosynthesis and carbohydrate metabolism}

The HLB affected citrus leaves results in downregulation of important genes involved in photosynthesis processes. In the present study, we also showed that when diseased citrus leaves were treated with indigenous endophytes, only one of the gene ferrodoxin 3 (Ciclev10029499m.g) related to photosynthesis was up-expressed while two genes, APE1 (Ciclev10012434m.g) and PSB28 (Ciclev10022322m.g) related to acclimation of photosynthesis to environment and photosystem II reaction center, respectively were down-expressed indicating the pathogen is present inside the diseased leaves. Significant genes responsible for ethylene (Ciclev10000608m.g, Ciclev10014617m.g, Ciclev10031204m.g) were upregulated. HLB causes accumulation of starch inside the phloem and other photosynthetic cells, resulting in blockage of important nutrients inside leaves. We found that our endophytes treatment resulted in downregulation of beta glucosidase 46 (Ciclev10014887m.g) and beta glucosidase 11 (Ciclev10019719m.g), which are responsible for starch accumulation. It has been reported that Clas pathogen negatively affected the metabolism of carbohydrate inside citrus trees. The present study found that some of the genes were upregulated related to carbohydrate metabolism when endophytes application was employed. Significant genes are aldehyde dehydrogenase 3F1 (Ciclev10025492m.g), Galactose mutarotase (Ciclev10012004m.g),GroES-like zinc-binding dehydrogenase (Ciclev10020620m.g), hydroxymethylglutaryl-CoA synthase / HMG-CoA synthase / 3-hydroxy-3methylglutaryl coenzyme A synthase (Ciclev10020042m.g), Alpha amylase(Ciclev10007401m.g), arginosuccinate synthase (Ciclev10019860m.g), and phosphoglucose isomerase 1 (Ciclev10000603m.g) with log fold change (LFC) of 1.77, 1.69, 1.57, 1.47, 1.45, 1.14, and 1.01, respectively, with FDR (padj<0.05) (Table S9).

\section{Related to cell wall breakdown}

The genes involve in cell wall breakdown are mostly expressed in the citrus leaves affected with huanglongbing, indicating the symptoms development are associated with these genes in HLB 
progression. The cellulose/transferases are all associated with the cell wall breakdown. Our study indicated that cellulose synthase/transferases (Ciclev10007586m.g, Ciclev10023570m.g, Ciclev10014586m.g) genes are down regulated after applying endophytes, which is the main genes in breakdown of cell wall (Table S10).

\section{Transcription factors}

A total of 23 important transcription factors were identified when citrus trees were treated with endophytes (Table S11). Among them 18 TFs are upregulated and 5 are down-expressed. These transcription factors has important role in plant defense response, biotic and abiotic stress, plant immunity, leaf senescence, stomatal movement, and jasmonate metabolism. Several families of transcription factors, such as WRKY $(11,28,33,40,50,55)$, MYB $(1,15,116)$, and EIN3

(Ciclev10000608m.g) are associated with the plant immunity and defense up-expressed in the citrus trees after endophyte treatments. The WRKYs transcription factors are also involved in the tolerance to Clas pathogen in citrus. Heat shock transcription factor A4A (Ciclev10015413m.g) and heat shock transcription factor A8 (Ciclev10015541m.g) are up-expressed in the citrus leaves indicating the important regulator in several environmental stress. The other important TFs responsible for plant defense mechanism are respiratory burst oxidase homologue D (Ciclev10027774m.g) and Leucine-rich repeat protein kinase family protein (Ciclev10019897m.g), expressed to a log fold change of 4.02 and 2.29 , respectively (padj<0.05) (Table S11).

\section{Discussion}

In order to demonstrate specific role of endophytes to manage more devastating disease of citrus, we isolated and identified indigenous endophytes from the different symptomatic, asymptomatic and healthy leaves from different locations of citrus growing regions in China [26]. Endophyte with maximum growth-inhibitory effects, L1-21 belonging to Bacillus subtilis, was chosen as surrogate's strain to manage the citrus HLB in the field. We tested efficacy of $B$. subtilis L1-21, which showed marked pink colonies differences among all isolated endophytes, resulting in as an indicator endophyte isolated from citrus trees in the experimental fields. Novel half-leaf method advanced understanding of pathogen exclusion within the midrib. Presence of the endophyte in the citrus leaf midrib excluded the pathogen, indicating its role in plant defence by limiting pathogen survival or transmission inside the host plant. In in vitro experiment, we sprayed endophytes on diseased citrus leaves, and $4 \mathrm{~d}$ after application, pathogen copy density had been reduced 1000 -fold times, representing 100\% disease control compared with the negative control. These results indicate disease suppression activities, such as retardation of quorum sensing activities by pathogen diffusible antibacterial compounds, nutrient competition, plant growth hormones, siderophores that chelate toxic materials, and competition for survival, may have occurred with field applications of endophytes, need to study in more detail that limited in planta transmission of the pathogen. Endophyte application positively regulated other microbes in citrus leaves, indicating native bacteria diversity was unaffected. It is likely that healthy and asymptomatic citrus trees harbour disease suppressive endophytic bacteria that may resist antimicrobial compounds in the host plant phloem and, 
perhaps, contribute to protection against the Clas pathogen. We found there was no effect on Clas copy density in diseased citrus leaves of treatment with LB and water as controls, indicating that reduction of the pathogen within the leaf was due to application of $B$. subtilis L1-21. Citrus endophytes, such as Methylobacterium and Sphingomonas, are involved in the protection of plants against various devastating pathogens[27, 28].

The reduction of the pathogen is associated with competition for the nutrients among pathogen and endophytes, substances release by endophytes that could have possible interference with the pathogen quorum-sensing signaling [29,30]. Endophyte colonization in citrus host reduce Clas pathogen or their colonization could be retarded due to substances in the form of antibiotics or lipopeptides, bacteriocin proteins produce via endophytes [31]. Core microbiomes present in citrus host may be regulated by these endophytes, creating possibility to stop colonization of pathogen, most probably through induced systemic resistance (ISR) [32, 33]. Further, systemic resistance in host against pathogen is generated through specialized bioactive compounds synthesized by endophytes [34].

Currently, Clas pathogen was reduced due to use of antibiotics (Oxytetracycline hydrochloride, Penicillin G potassium, Ampicillin and others) in the greenhouse and field experiments but these are phytotoxic and persist as residues inside fruits $[35,36]$. Our field experiment demonstrated successful management of Clas pathogen in HLB-diseased citrus with regular applications of $B$. subtilis L1-21. Pathogen copy density in the diseased trees was reduced to $<10 \mathrm{~g}^{-1}$ of leaf midrib, and growth of green leaves and shoots was increased, including in previously moribund trees (Fig. S4); similarly, marketable fruit yields improved. However, the underlying mechanisms of effects of endophytes on reductions in Clas copy density and disease development remain unclear. We assume that reduction of the pathogen may be related to increase within-plant endophyte density, because previous work has shown that Clas present inside citrus leaves regulated HLB symptoms positively and the leaf microbiome negatively [17, 24]. Pathogen exclusion effects were related to the increased density of $B$. subtilis L1-21 within the diseased trees, due to application of the endophyte treatment. To determine in planta endophyte interactions with Clas, we first quantified their pre-treatment densities in the diseased trees. Following treatment with $B$. subtilis L1-21, there were increases in endophyte densities in the citrus trees and lower densities of pathogens. Notably, high copy densities of Clas remained present in diseased trees that were not treated with the endophyte. Thus, our study confirmed that population dynamics of native citrus bacteria affected Clas pathogen titers $[14,23]$.

The diseased citrus trees after application of endophytes resulted in up-regulation of important genes in citrus plants responsible for pathogen/disease resistance, chaperone family protein, and respiratory burst oxidase. The differentially expressed pathogen resistance genes involved in different pathways help the plant defense during biotic stress. Diverse mechanisms present in plants keep away pathogen and parasite from attack. Most important are dominant disease resistance (R) genes which encodes for leucine-rich repeat (NB-LRR) proteins providing resistance to pathogens through avirulence (Avr) genes [37]. Activation of 3 disease resistance genes (CC-NBS-LRR) (RPS5) may induce the defense response against pathogen. None of the RPS5 gene was activated in the citrus trees without endophytes. 
Resistance to citrus HLB is generated in host through over expression of an Arabidopsis NPR1 [38] also supported our findings. Combination of these pathogen resistance genes can uplift the citrus plants against HLB more easily rather functioning alone. Nine molecular mechanism are elucidated recently about the mechanisms involved in resistance genes against the attack of pathogens [39]. There is direct perception of the pathogen associated molecular patterns (PAMPs), that are linked to partial or full disease resistance to pathogen. Our results indicate that strengthening the bacterial endophytic microbiome of diseased citrus trees may improve the management of Clas in HLB-infected trees.

\section{Conclusions}

Clas pathogen density in citrus trees is driven by an inversely proportional density of endophytes. Potential endophyte $B$. subtilis L1-21 for the management of citrus HLB using novel half-leaf method in vitro demonstrated that treatment of diseased citrus leaves with the endophyte reduced pathogen density in diseased leaf midribs by 1000 -fold. Based on the results presented here, how the potential endophyte leads to restructuring of bacterial endophyte in diseased citrus groves are presented in Fig. 7. In the field experiments, regular applications of the endophyte resulted in reductions in diseased citrus canopy from $>90 \%$ to $<3 \%$ within a year, and diseased trees began to develop new shoots, healthy green leaves and yielded marketable fruits. Pathogen inside diseased trees was reduced by the endophyte to a level that elicited economic benefits to the farmer. Although the suppressive mechanism of endophyte against pathogen requires further exploration, however, we gained more insights about multiple activated disease resistance and secondary metabolites genes in HLB-affected citrus trees that lead to defence against pathogen post-treatment with endophyte. Several genes including photosynthesis, carbohydrate and those involved in cell wall breakdown have role in controlling Clas disease progression were downregulated after application of potential endophyte. Our study is the first initiative to highlight restructuring of the citrus bacterial endophytes by indigenous endophytes to mitigate the devastating disease HLB in economically important citrus crops.

\section{Methods}

\section{Bacterial strain and culture conditions}

The endophytic strain $B$. subtilis L1-21, for which the genome has been sequenced, was selected for the greenhouse and citrus field experiments (Binchuan, Yunnan province, China). The endophyte $B$. subtilis L1-21 was stored in $40 \%$ glycerol $(\mathrm{v} / \mathrm{v})$ at $-80^{\circ} \mathrm{C}$; stock culture was renewed every 4 months on LB agar and cultivated for 24-48 $\mathrm{h}$ to check stability of the potential endophyte. A pure culture of L1-21 was grown until the late log phase in LB broth for $24-48 \mathrm{~h}$ at $37^{\circ} \mathrm{C}$ in a shaking incubator $(150 \mathrm{rpm})$. The colony forming units ( $\mathrm{cfu} \mathrm{ml}^{-1}$ ) of the endophyte were checked using contrasting dilutions in sterile distilled water with $0.1 \%$ Tween 20 and plated on LB agar before foliar spraying on the citrus trees.

\section{Novel half-leaf method}


We designed a novel citrus half-leaf method to quantify leaf Clas copy density prior to and after treatment application. Firstly, DNA was extracted from one half of a diseased leaf using the CTAB method $[24,40]$, and conventional PCR analysis, using the primer set Cal-R/Cal-F[41], was followed by nested PCR analysis, using the primer set CG03F/CG05R[42], for confirmation of "Ca. Liberibacter asiaticus". Primers used in this study are listed in Extended Table S1. Once confirmed as infected with the Clas pathogen, the other half of the citrus leaf was treated with $10^{4}-10^{6} \mathrm{cfu} \mathrm{ml}^{-1}$ of endophytes in a 5-mL Eppendorf tube and the antibiotics penicillin $\left(100 \mu \mathrm{g} \mathrm{ll}^{-1}\right)$ dissolved in distilled water, spinosad $\left(100 \mu \mathrm{g}^{-1}\right)$ dissolved in hexane solution and shenqimycin $\left(100 \mu \mathrm{g} \mathrm{\mu l}^{-1}\right)$ dissolved in distilled water as positive controls. LB and distilled water were used as negative controls. The Eppendorf tubes were kept for $96 \mathrm{~h}$ at room temperature, followed by extraction of DNA from the leaf midribs. The $16 \mathrm{~S}$ rDNA gene was amplified as discussed previously [24]. The weight of each half leaf was recorded prior to the experiment. Each treatment comprised three replicate Eppendorf tubes that each contained six diseased citrus leaves. The experiment was repeated five times. Treatment effects on Clas pathogen were tested by loading the amplified product on $1 \%$ agarose gel. In another experiment testing for Clas pathogen and endophytes elevation, DNA was extracted from one half of a diseased leaf using the CTAB method [40] and amplified with the same primers as previously. Once the leaf was confirmed as infected with Clas, the other half of the leaf was kept in a 180-mm Petri dish with $10^{4}$ and $10^{6} \mathrm{cfu} \mathrm{ml}^{-1}$ of endophytes or penicillin $\left(100 \mu \mathrm{g} \mathrm{ll}^{-}\right.$ $\left.{ }^{1}\right)$ dissolved in distilled water. LB and distilled water were used as controls. The Petri dishes were kept at room temperature; then, DNA was extracted from the midribs and present endophytes were isolated. Briefly, for endophyte isolation, leaves were washed in tap water and surface sterilized using $35 \%$ bleach $\left(2 \%\right.$ active $\left.\mathrm{Cl}^{\square}\right)$ and $70 \%(\mathrm{vol} / \mathrm{vol})$ ethanol for 2 min each; then, the leaves were rinsed three times in sterile water $[13,40]$. The weight of each leaf half was recorded prior to the experiment. Each treatment comprised three replicates of 12 diseased citrus leaves ( 6 random top and bottom half leaves, each), and the experiment was repeated five times. Changes in Clas copy density were tested from 0-4 $d$, based on Ct values of pathogen copies $\mathrm{g}^{-1}$ of citrus leaf that were calculated using the standard curve generated previously; changes in endophyte density were recorded daily as log cfu $\mathrm{g}^{-1}$ of citrus leaf midrib.

\section{Real-time PCR analysis of half-leaf data}

The PCR reaction was performed in a $25-\mu$ l reaction mixture containing $1 \times$ PCR buffer (SYBR Green Master Mix; Bio-Rad), $0.8 \mu \mathrm{l}$ of each primer (CQULA04R/CQULA04F) and the appropriate amount of DNA template in a RT-PCR system (Step One Real Time PCR System, Applied Biosystems, United States) used the following programme: $95^{\circ} \mathrm{C}$ for $1 \mathrm{~min}, 45$ cycles at $95^{\circ} \mathrm{C}$ for $15 \mathrm{~s}, 59^{\circ} \mathrm{C}$ for $15 \mathrm{~s}$ and $72{ }^{\circ} \mathrm{C}$ for $45 \mathrm{~s}$. During the extension step $\left(72^{\circ} \mathrm{C}\right.$ for $\left.45 \mathrm{~s}\right)$ of each cycle, the instrument collected a fluorescent signal generated from SGI fluorescent dye that was non-specifically bound to dsDNA. To analyze PCR amplification specificity, a melt-curve analysis was conducted as follows: $95^{\circ} \mathrm{C}$ for 1 min and $55^{\circ} \mathrm{C}$ for 1 min; then, the temperature was increased by $0.5^{\circ} \mathrm{C}$ every $10 \mathrm{~s}$ from 55 to $95^{\circ} \mathrm{C}$. The melt curve was plotted according to the manufacturer's instructions (Bio-Rad, United States). The recombinant plasmid was constructed and a standard curve was generated accordingly [43]. 


\section{Study site and sample processing}

The experimental field site was located at Binchuan, Dali City, Yunnan province, China $\left(100.5754^{\circ} \mathrm{E}\right.$, $25.8272^{\circ} \mathrm{N}$ ), with an average annual temperature of $33-35^{\circ} \mathrm{C}$ and total annual rainfall of about 1000 $\mathrm{mm}$. Foliar symptoms in one citrus grove, 16 years old, indicated $>90 \%$ severe Clas disease infection, and the second citrus grove, 4 years old, which was located $2 \mathrm{~km}$ from the first, exhibited $100 \%$ Clas infection. Two field trials were conducted from 2017-19: in one citrus grove, 162 trees (Fig. 2) were treated with contrasting treatments; and in the second grove, 93 of 525 trees were selected (three replicates of 31 trees) for Clas titer test. Prior to the start of each trial, a field survey was carried out to visually determine individual tree HLB severity and quantify Clas titers using Clas-specific primers in PCR and qPCR analyses. The soil treatments at the citrus groves comprised Fertilizer 1 (rape seed cape with Bacillus amyloliquefaciens $\mathrm{Y} 2$, as a root-growth promoting agent); Fertilizer 2 (rape seed cape without Bacillus amyloliquefaciens $\mathrm{Y} 2)$; and, no rape seed cape as a control $\left(\mathrm{F}_{0}\right)$. We applied $5 \mathrm{~kg}$ of fertilizer to each tree around a water drip of about $20 \mathrm{~cm}$ deep. The antibiotic, and endophytes are listed in Table S2.

\section{Field endophyte treatment application}

Two injection ports per tree, located at the opposite sides of the trunk at approximately $20 \mathrm{~cm}$ above the union bud, were made by drilling $30 \mathrm{~mm}$ into the xylem tissue using a 7.14-cm drill bit. Antibiotic and endophyte treatments were injected from a pressurized bottle into each port using a drip micro infusioner at the recommended pressure ( $<50 \mathrm{psi}$ ). The first injection was done with penicillin $(0.1 \%)$ for $4 \mathrm{~d}$ on 54 trees, with 27 trees as a control. The second injection was done 2 weeks after the antibiotic treatment with the endophyte $\left(10^{6} \mathrm{cfu} \mathrm{ml}^{-1}\right)$ on 54 trees. We also applied $10^{6} \mathrm{cfu}$ of the endophyte $\mathrm{ml}^{-1}$ or penicillin as a monthly foliar spray on 27 trees for each treatment, until all leaves were wet, in the early morning or late evening. All the experiments were arranged as three replicates of three trees in a randomized complete block design.

\section{Isolation of endophytes from citrus trees}

The diversity of endophytic bacteria was estimated from three replicates of six citrus tree leaves that were removed from the trees and transported to the laboratory in a cooler with ice. Leaf samples were immediately washed in tap water to remove soil and then immersed in 70\% ethanol for $30 \mathrm{~s}$, washed with fresh sodium hypochloride solution ( $2.5 \%$ available $\left.\mathrm{Cl}^{-}\right)$for $1 \mathrm{~min}$, rinsed in $70 \%$ ethanol for $30 \mathrm{~s}$ and washed three times with sterile distilled water. As a sterility check, a 100- $\mu$ l sample of the third rinse water was plated onto Luria Bertani (LB) medium[40]. For isolation of endophytes, $1 \mathrm{~g}$ of leaf material was macerated in $9 \mathrm{ml}$ of sterilized distilled water using a sterilized mortar and pestle. The homogenate was used to make serial dilutions and $100 \mu \mathrm{l}$ of $10^{2}-10^{5} \mathrm{cfu} \mathrm{ml}^{-1}$ was plated on LB agar. Endophytes were isolated from three replicates of treatment samples collected on the first week of each month in 2017-18. Changes in endophyte density and Clas titer were recorded; number of endophytes were counted and expressed as cfu $\mathrm{g}^{-1}$ of citrus leaf. 


\section{Clas DNA extraction and PCR amplification}

Leaf samples from all treatments were collected monthly from the citrus groves to quantify Clas titer. Leaves were treated as above before DNA extraction. Methods for DNA extraction, PCR and qPCR were those described previously.

\section{Citrus tree growth conditions and treatments in the greenhouse}

Citrus mandarin plants were grown under glasshouse conditions and diseased (D vs LD) and healthy trees (H vs LH) were selected based on qPCR analysis of pathogen copy density, as described previously. Plants were grown in similar soil conditions in plastic pots $(310 \times 210 \mathrm{~mm}$; height and width), and leaves were collected at 0 and $6 \mathrm{~h}$ after foliar spraying with the endophyte concentration of $10^{5} \mathrm{cfu} \mathrm{ml}^{-1}$. We randomly collected three replicates of six leaves from each citrus tree. In addition, same number of leaves were stored for each of the treatment at $-80^{\circ} \mathrm{C}$.

\section{RNA extraction, library construction and sequencing}

Frozen citrus leaves were milled to a powder in a mortar with liquid nitrogen. Total RNA was extracted and mRNA was enriched by removing rRNA using a Ribo-ZeroTM Magnetic Kit (Epicentre). RNA fragmentation was performed in the presence of fragmentation buffer and CDNA was extracted by reverse transcription. Then, second-strand cDNA were synthesized by DNA polymerase I, RNase H, dNTP and a buffer, and the cDNA fragments were purified with a QiaQuick PCR extraction kit and end repaired, to which poly (A) was added and ligated to Illumina sequencing adapters. The ligation products were size selected by agarose gel electrophoresis, amplified by PCR and sequenced using Illumina HiSeqTM2500 by Gene Denovo Biotechnology Co. (Guangzhou, China). Raw sequencing data has been deposited to the Sequence Read Archive (SRA) under BioProject PRJNA640485 and is available at the following revieweraccess link: https://www.ncbi.nIm.nih.gov/bioproject/PRJNA640485/. Metadata file related to these deposited sequences have been included as additional file 1.

\section{Differentially expressed genesanalysis}

The edgeR package (http://www.r-project.org/) was used to identify differentially expressed genes (DEGs) across three biological replicates per treatment. We identified genes with a fold change $\geq 2$ and a false discovery rate (FDR) $<0.05$ as significant DEGs that were then subjected to enrichment analysis of GO functions and KEGG pathways[44]. All DEGs were mapped to GO terms in the Gene Ontology database (http://www.geneontology.org/), gene numbers were calculated for every term and significantly enriched GO terms in DEGs compared to the genome background were defined by hypergeometric distribution. The calculated $p$-value was FDR corrected, where FDR $\leq 0.05$ was the threshold.

\section{Statistical analysis}

Endophytic bacteria populations were calculated, based on average logarithm (base 10) cfu values, and analysed using GraphPad Prism 5 (San Diego, CA, USA). Pathogen copies $\mathrm{g}^{-1}$ of diseased citrus leaf 
material were calculated using a standard curve value. Treatment effects were tested using analysis of variance in IBM SPSS Statistics 22.0, and treatment means were compared using Duncan's multiple range test at $\mathrm{P}<0.05$.

\section{Declarations}

\section{Ethics approval and consent to participate}

Not applicable.

\section{Consent for publication}

Not applicable.

\section{Availability of data and materials}

All data is available in the main text or the supplementary materials. Raw sequencing data has been deposited to the Sequence Read Archive (SRA) under BioProject PRJNA640485 and is available at the following reviewer-access link: https://www.ncbi.nlm.nih.gov/bioproject/PRJNA640485/. Metadata file related to these deposited sequences have been included as additional file 1.

\section{Competing interests}

The authors have no conflicting interests related to this manuscript.

\section{Funding}

This research was financially supported by Ministry of Science and Technology, China (2009DFA32360) and National Natural Science Foundation of China for International Young Scientist (32050410307).

\section{Author contributions}

S.M., Y.M.L., P.F.F., P.B.H., P.J.H., W.Y.C., Y.X.W., S.C.K. and X.Y.L. performed the laboratory experiments and data analyses. S.M., S.X.Z., Y.S.X., K.X.Z., Y.C.Y., Q.L., X.B.H., C.J.Z., S.C.Y., C.M., H.M.W. and Y.Q.H. performed field experiments and collected samples. Y.Q.H. and S.L.S supervised the study. S.M. and Y.Q.H. drafted the manuscript.

\section{Acknowledgments}

We thank all the members of the Binchuan Institute of Food and Medicines Inspection, Yunnan province, China for their valuable time during all the field experiments.

\section{References}


1. Wang N, Trivedi P. Citrus huanglongbing: a newly relevant disease presents unprecedented challenges. Phytopathology. 2013;103(7):652-65.

2. Bové JM. Huanglongbing: a destructive, newly-emerging, century-old disease of citrus. Journal of Plant Pathology 2006:7-37.

3. Keremane M, Ramadugu C, Castaneda A, Diaz J, Peñaranda E, Chen J, Duan Y, Halbert S, Lee R. Report of Candidatus Liberibacter caribbeanus, a new citrus-and psyllid-associated Liberibacter from Colombia, South America. In: American Phytopathological Society (APS) Annual Meeting, August: 2015. 1-5.

4. Duan Y, Zhou L, Hall DG, Li W, Doddapaneni H, Lin H, Liu L, Vahling CM, Gabriel DW, Williams KP. Complete genome sequence of citrus huanglongbing bacterium,'Candidatus Liberibacter asiaticus' obtained through metagenomics. Mol Plant Microbe Interact. 2009;22(8):1011-20.

5. Albrecht U, Bowman KD. Gene expression in Citrus sinensis (L.) Osbeck following infection with the bacterial pathogen Candidatus Liberibacter asiaticus causing Huanglongbing in Florida. Plant Sci. 2008;175(3):291-306.

6. Fan J, Chen C, Yu Q, Brlansky RH, Li ZG, Gmitter FG Jr. Comparative iTRAQ proteome and transcriptome analyses of sweet orange infected by "Candidatus Liberibacter asiaticus". Physiol Plant. 2011;143(3):235-45.

7. Pagliai FA, Gonzalez CF, Lorca GL. Identification of a ligand binding pocket in LdtR from Liberibacter asiaticus. Front Microbiol. 2015;6:1314.

8. Albrecht U, Fiehn O, Bowman KD. Metabolic variations in different citrus rootstock cultivars associated with different responses to Huanglongbing. Plant Physiol Biochem. 2016;107:33-44.

9. Zhang M, Powell CA, Guo Y, Doud MS, Duan Y. A graft-based chemotherapy method for screening effective molecules and rescuing huanglongbing-affected citrus plants. Phytopathology. 2012;102(6):567-74.

10. Yang C, Powell CA, Duan Y, Shatters R, Fang J, Zhang M. Deciphering the bacterial microbiome in huanglongbing-affected citrus treated with thermotherapy and sulfonamide antibiotics. PloS One. 2016;11(5):e0155472.

11. Hao G, Stover E, Gupta G. Overexpression of a modified plant thionin enhances disease resistance to citrus canker and huanglongbing (HLB). Frontiers in Plant Science 2016, 7:1078.

12. Zou $X$, Jiang $X, X u$ L, Lei T, Peng A, He Y, Yao L, Chen S. Transgenic citrus expressing synthesized cecropin $B$ genes in the phloem exhibits decreased susceptibility to Huanglongbing. Plant Mol Biol. 2017;93(4-5):341-53.

13. Munir S, Li Y, He P, He P, He P, Cui W, Wu Y, Li X, He Y. Bacillus subtilis L1-21 possible assessment of inhibitory mechanism against phytopathogens and colonization in different plant hosts. Pakistan Journal of Agricultural Sciences 2018, 55(4):996-1002.

14. Sagaram US, DeAngelis KM, Trivedi P, Andersen GL, Lu S-E, Wang N. Bacterial diversity analysis of Huanglongbing pathogen-infected citrus, using PhyloChip arrays and 16S rRNA gene clone library sequencing. Appl Environ Microbiol. 2009;75(6):1566-74. 
15. Trivedi P, He Z, Van Nostrand JD, Albrigo G, Zhou J, Wang N. Huanglongbing alters the structure and functional diversity of microbial communities associated with citrus rhizosphere. The ISME Journal. 2012;6(2):363.

16. Bulgari D, Casati P, Crepaldi P, Daffonchio D, Quaglino F, Brusetti L, Bianco PA. Endophytic bacterial community is restructured in grapevine yellows-diseased and recovered Vitis vinifera L. plants. Applied and Environmental Microbiology 2011:AEM. 00051 - 00011.

17. Blaustein RA, Lorca GL, Meyer JL, Gonzalez CF, Teplitski M. Defining the core citrus leaf-and rootassociated microbiota: Factors associated with community structure and implications for managing huanglongbing (citrus greening) disease. Applied and Environmental Microbiology 2017:AEM. 00210-00217.

18. Andreote FD, Da Rocha UN, Araújo WL, Azevedo JL, van Overbeek LS. Effect of bacterial inoculation, plant genotype and developmental stage on root-associated and endophytic bacterial communities in potato (Solanum tuberosum). Antonie Van Leeuwenhoek. 2010;97(4):389-99.

19. Dematheis F, Kurtz B, Vidal S, Smalla K. Multitrophic interactions among Western Corn Rootworm, Glomus intraradices and microbial communities in the rhizosphere and endorhiza of maize. Front Microbiol. 2013;4:357.

20. Herschkovitz Y, Lerner A, Davidov Y, Rothballer M, Hartmann A, Okon Y, Jurkevitch E. Inoculation with the plant-growth-promoting rhizobacterium Azospirillum brasilense causes little disturbance in the rhizosphere and rhizoplane of maize (Zea mays). Microb Ecol. 2005;50(2):277-88.

21. Schreiter S, Sandmann M, Smalla K, Grosch R. Soil type dependent rhizosphere competence and biocontrol of two bacterial inoculant strains and their effects on the rhizosphere microbial community of field-grown lettuce. PLoS One. 2014;9(8):e103726.

22. Zhang M, Powell CA, Benyon LS, Zhou H, Duan Y. Deciphering the bacterial microbiome of citrus plants in response to 'Candidatus Liberibacter asiaticus'-infection and antibiotic treatments. PloS One. 2013;8(11):e76331.

23. Zhang M, Guo Y, Powell C, Doud M, Yang C, Zhou H, Duan Y. Zinc treatment increases the titre of 'Candidatus Liberibacter asiaticus' in huanglongbing-affected citrus plants while affecting the bacterial microbiomes. J Appl Microbiol. 2016;120(6):1616-28.

24. Munir S, Li Y, He P, He P, He P, Cui W, Wu Y, Li X, He Y. Seasonal variation and detection frequency of Candidatus Liberibacter asiaticus in Binchuan, Yunnan province China. Physiol Mol Plant Pathol. 2019;106:137-44.

25. Rastogi G, Sbodio A, Tech JJ, Suslow TV, Coaker GL, Leveau JH. Leaf microbiota in an agroecosystem: spatiotemporal variation in bacterial community composition on field-grown lettuce. The ISME Journal. 2012;6(10):1812.

26. Munir S, Li Y, He P, Huang M, He P, He P, Cui W, Wu Y, He Y. core endophyte communities of different citrus varieties from citrus growing regions in China. Sci Rep. 2020;10(1):1-12.

27. Ardanov P, Sessitsch A, Häggman H, Kozyrovska N, Pirttilä AM. Methylobacterium-induced endophyte community changes correspond with protection of plants against pathogen attack. PLoS One. 
2012;7(10):e46802.

28. Innerebner G, Knief C, Vorholt JA. Protection of Arabidopsis thaliana against leaf-pathogenic Pseudomonas syringae by Sphingomonas strains in a controlled model system. Appl Environ Microbiol. 2011;77(10):3202-10.

29. Piewngam P, Zheng Y, Nguyen TH, Dickey SW, Joo H-S, Villaruz AE, Glose KA, Fisher EL, Hunt RL, Li B. Pathogen elimination by probiotic Bacillus via signalling interference. Nature 2018:1.

30. Miller MB, Bassler BL. Quorum sensing in bacteria. Annual Reviews in Microbiology 2001, 55(1):165-199.

31. Kamada N, Chen GY, Inohara N, Núñez G. Control of pathogens and pathobionts by the gut microbiota. Nat Immunol. 2013;14(7):685.

32. Pertot I, Puopolo G, Hosni T, Pedrotti L, Jourdan E, Ongena M. Limited impact of abiotic stress on surfactin production in planta and on disease resistance induced by Bacillus amyloliquefaciens S499 in tomato and bean. FEMS Microbiol Ecol. 2013;86(3):505-19.

33. Zhao L, Xu Y, Lai X. Antagonistic endophytic bacteria associated with nodules of soybean (Glycine max L.) and plant growth-promoting properties. Brazilian Journal of Microbiology 2018, 49(2):269278.

34. Guo B, Wang Y, Sun X, Tang K. Bioactive natural products from endophytes: a review. Appl Biochem Microbiol. 2008;44(2):136-42.

35. Zhang M, Guo Y, Powell CA, Doud MS, Yang C, Duan Y. Effective antibiotics against 'Candidatus Liberibacter asiaticus' in HLB-affected citrus plants identified via the graft-based evaluation. PloS One. 2014;9(11):e111032.

36. Munir S, He P, Wu Y, He P, Khan S, Huang M, Cui W, He P, He Y. Huanglongbing Control: Perhaps the End of the Beginning. Microb Ecol. 2018;76(1):192-204.

37. Postel S, Kemmerling B. Plant systems for recognition of pathogen-associated molecular patterns. In: Seminars in cell \& developmental biology: 2009. Elsevier: 1025-1031.

38. Dutt M, Barthe G, Irey M, Grosser J. Transgenic citrus expressing an Arabidopsis NPR1 gene exhibit enhanced resistance against Huanglongbing (HLB; Citrus Greening). PloS One. 2015;10(9):e0137134.

39. Kourelis J, van der Hoorn RA. Defended to the nines: 25 years of resistance gene cloning identifies nine mechanisms for R protein function. Plant Cell. 2018;30(2):285-99.

40. Araújo WL, Marcon J, Maccheroni W, van Elsas JD, van Vuurde JW, Azevedo JL. Diversity of endophytic bacterial populations and their interaction with Xylella fastidiosa in citrus plants. Appl Environ Microbiol. 2002;68(10):4906-14.

41. Jagoueix S, Bové JM, Garnier M. PCR detection of the two «Candidatus» liberobacter species associated with greening disease of citrus. Mol Cell Probes. 1996;10(1):43-50.

42. Zhou L, Gabriel D, Duan Y, Halbert S, Dixon W. First report of dodder transmission of huanglongbing from naturally infected Murraya paniculata to citrus. Plant Dis. 2007;91(2):227-7. 
43. Wang Z, Yin Y, Hu H, Yuan Q, Peng G, Xia Y. Development and application of molecular-based diagnosis for 'Candidatus Liberibacter asiaticus', the causal pathogen of citrus huanglongbing. Plant Pathol. 2006;55(5):630-8.

44. Kanehisa M, Araki M, Goto S, Hattori M, Hirakawa M, Itoh M, Katayama T, Kawashima S, Okuda S, Tokimatsu T. KEGG for linking genomes to life and the environment. Nucleic Acids Res. 2007;36(suppl_1):D480-4.

\section{Figures}



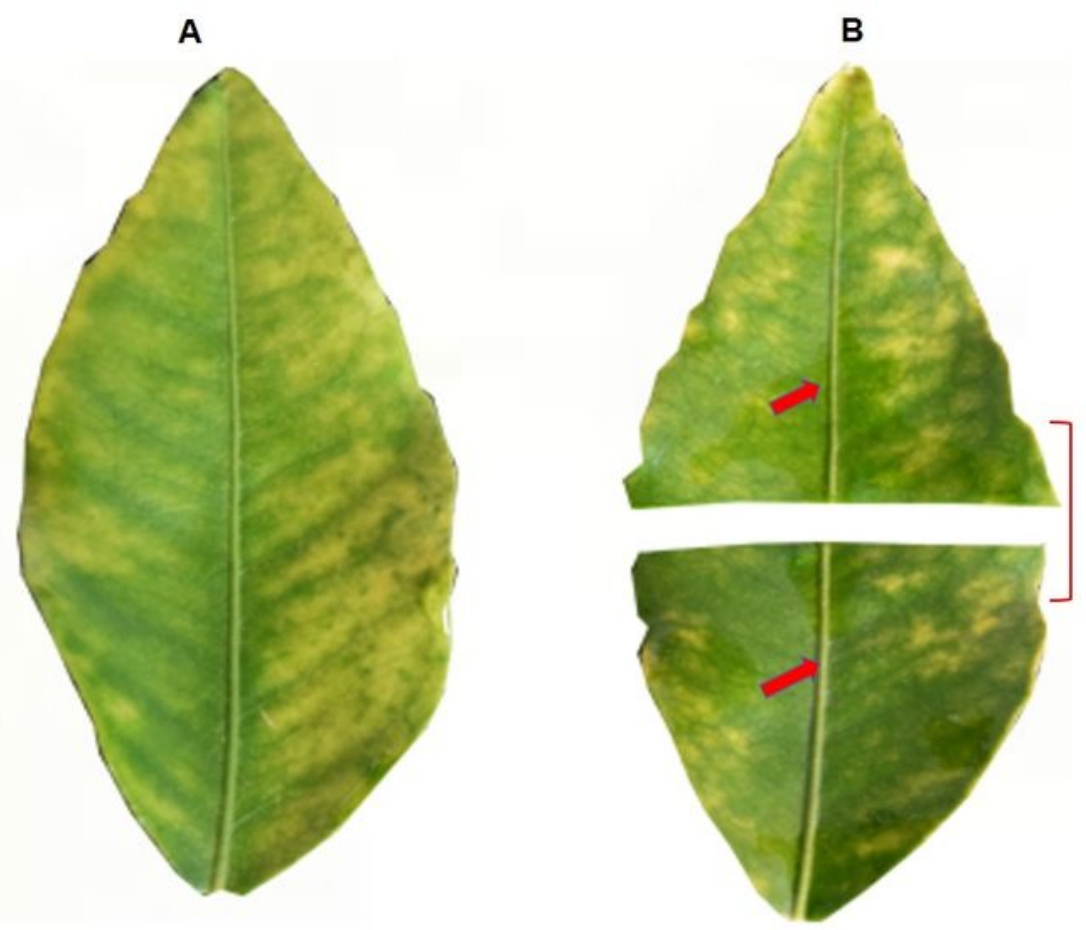

C $\begin{array}{llllllllll}1 & 2 & 3 & 4 & 5 & 6 & 7 & 8 & 9 & 10\end{array}$

$\mathbf{E}$

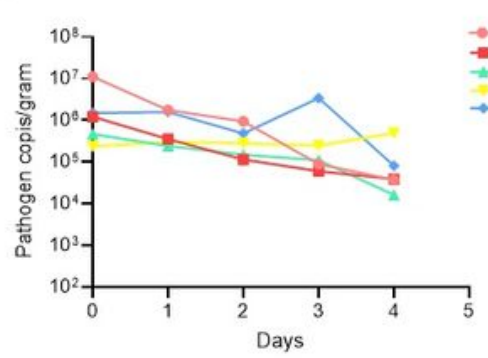

G

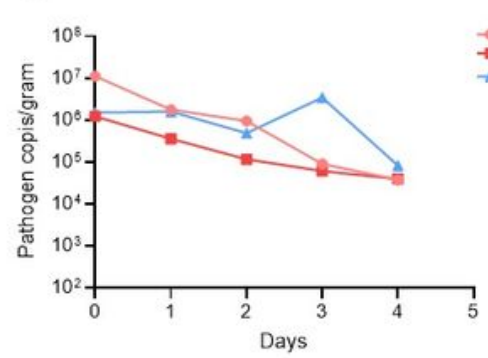

D

$\begin{array}{llllllllllllllll}1 & 2 & 3 & 4 & 5 & 6 & 7 & 8 & 9 & 10 & 11 & 12 & 13 & 14 & 15 & 16\end{array}$
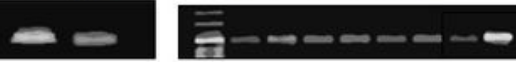

$\mathbf{F}$

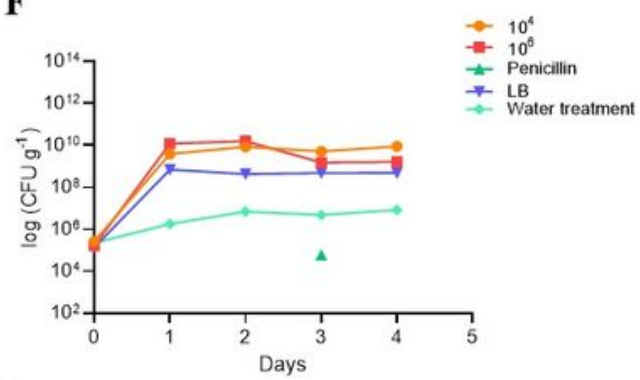

$\mathbf{H}$

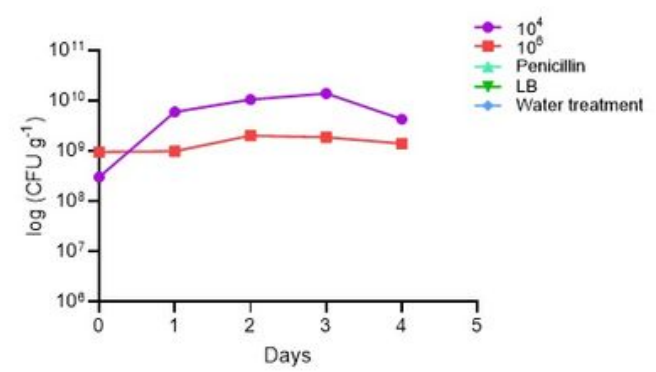

\section{Figure 1}

Citrus half leaf method for reduction of Clas and elevation of endophytes in the diseased citrus leaves from 0-4 days. Sketch of citrus leaf used in novel citrus-half leaf experiment. (A) whole citrus leaves showing HLB symptoms; (B) leaf was parted into two parts; the first part was used to detect the Clas pathogen using conventional and QPCR; after confirmation the second part was used in the experiment for B. subtilis L1-21 treatment. Red arrows indicate leaf midribs used for extraction of DNA for 
convetional and qPCR;(C) diseased citrus leaves were treated with endophytes (103-106 cfu/ml) and antibiotics such as penicillin (100 $\mu \mathrm{g} \mu \mathrm{l}-1$ and $500 \mu \mathrm{g} \mu \mathrm{l}-1)$, shenqinmycin $(100 \mu \mathrm{g} \mu \mathrm{l}-1)$ and spinosad(100 $\mu \mathrm{g} \mu \mathrm{l}$-1); Lane 9, water control; Lane 10, positive control; (D) before application; Lane 1, citrus leaf sample treated with Penicillin; Lane 2, leaf samples treated with spinosad; Lane 3, citrus leaves treated with shenqinmycin; Lane 4, sample in LB medium treated with the endophytes without shaking; Lane 5, 6, samples in LB medium and water respectively on shaker; Lane 7, diseased citrus leaf in water only; Lane 8, positive control; After application: Lane 9, indicated reduction of Clas pathogen with different treatments including penicillin; Lane 10, spinosad; Lane 11, shenqinmycin; Lane 12, endophyte treatment in LB medium without shaking; Lane 13, endophyte treatment in LB medium with shaking; Lane 14, samples in water on with shaking (E) pathogen copies per gram of leaves midrib using 104 and 106 $\mathrm{cfu} / \mathrm{ml}$ of endophyte treatment one time. Pathogen copies/gram were calculated based on the standard curve of recombinant plasmid pUC18-382-HLB generated through qPCR. Penicillin was used as a positive control. LB medium and water were used as negative control treatments. Three biological replicates were used for each treatment and each replicate consisted of 12 diseased leaves(including 6 top and bottom half leaves each). The experiment was repeated five times; (F), other endophytes diversity in the diseased citrus leaves after application of endophytes and penicilin; $(\mathrm{G})$ pathogen copies per gram of leaves using 104 and $106 \mathrm{cfu} / \mathrm{ml}$ of endophyte and water treatment one time; $(\mathrm{H})$ recovery of treated endophytes from the diseased citrus leaves during different time intervals with different treatments. The populations of endophytic bacteria were calculated based on average logarithm (base 10) of bacteria recovered from the plant leaves. The detection limit ( 1 x $102 \mathrm{cfu} /$ leaves) was treated as log 0 for mean calculation. The log cfu values were analyzed with GraphPad Prism 5 (San Diego, CA, USA). The values are the means \pm the standard deviation of 4 replicates with statistical significance difference among different treatments $(P \leq$ 0.05).

A

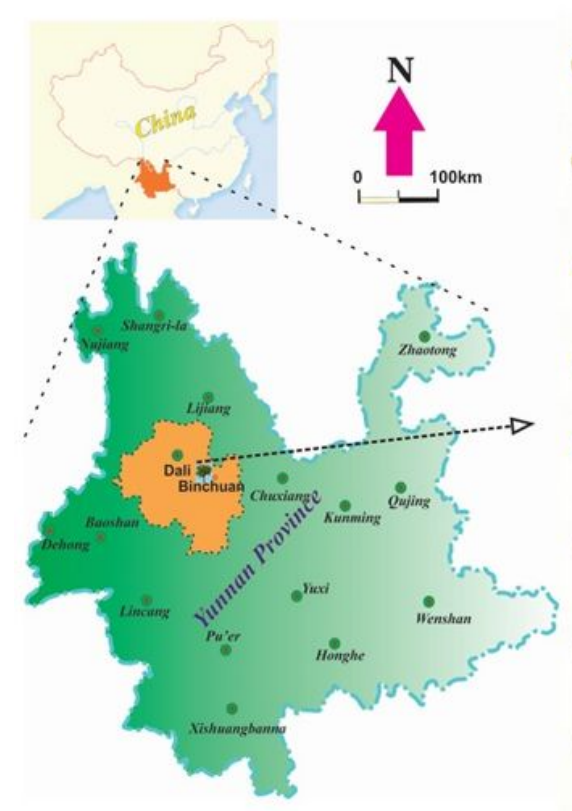

B
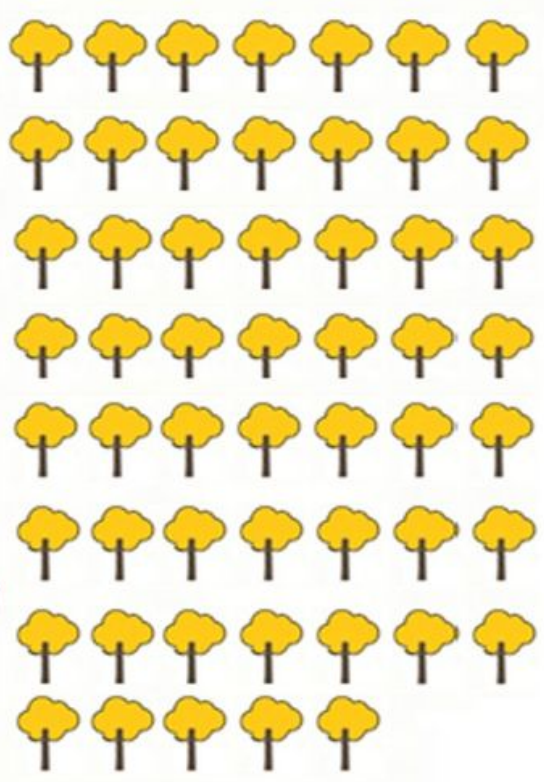

C
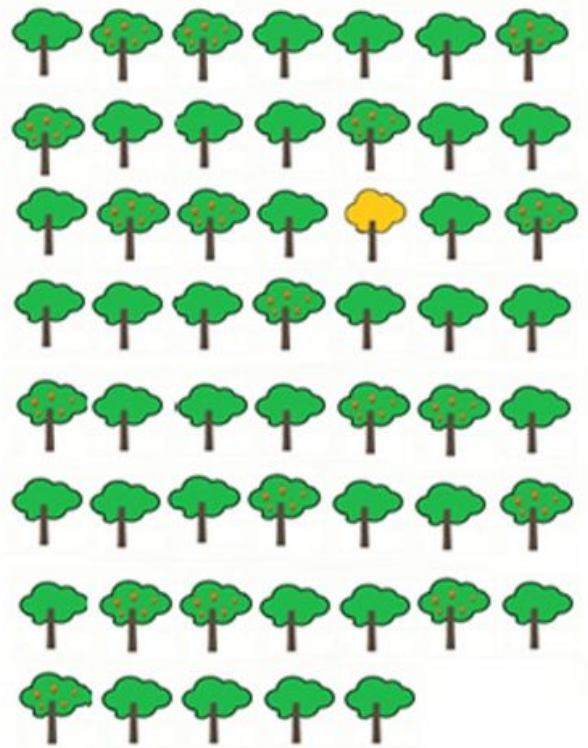

Figure 2 
Inhibition and exclusion of Clas pathogen in diseased fields after application of B. subtilis L1-21. (A) area with blue colour represents the citrus fields where the experiments were performed in diseased citrus trees; (B) diseased citrus fields (yellow colour displayed HLB affected trees) before endophyte B. subtilis L1-21 application. A total of 162 diseased citrus trees were treated with the endophyte; (C) green trees, and trees with orange fruit depicted the control effect in diseased citrus trees. One citrus tree present in the figure represents a total of three trees in the field. B. subtilis L1-21 shown in pink colour represent its characteristics colony morphology. Note: The designations employed and the presentation of the material on this map do not imply the expression of any opinion whatsoever on the part of Research Square concerning the legal status of any country, territory, city or area or of its authorities, or concerning the delimitation of its frontiers or boundaries. This map has been provided by the authors.

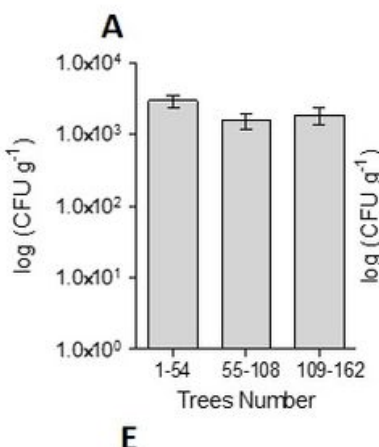

$\mathrm{E}$

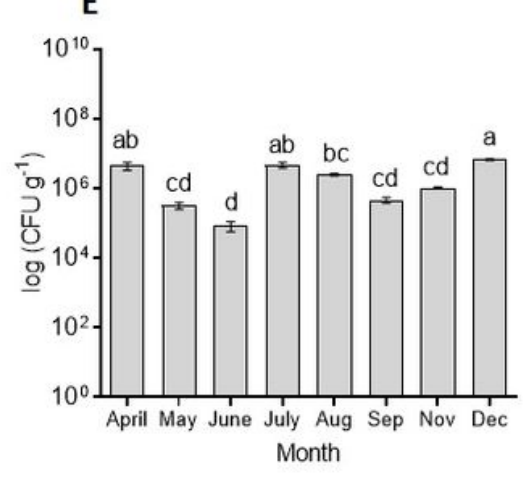

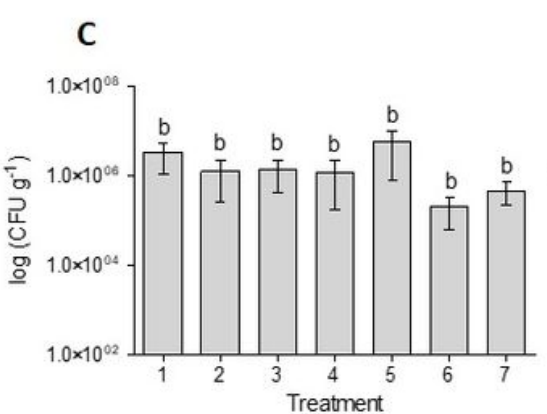

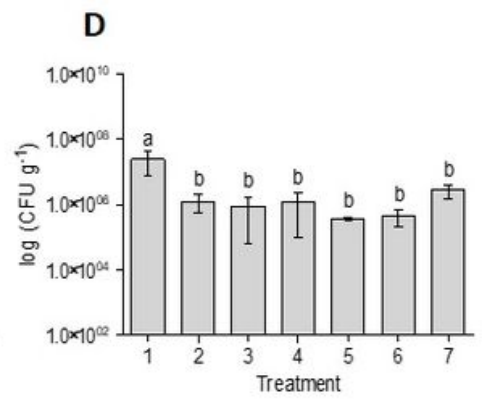

\section{Figure 3}

Endophytes diversity and reduction of Clas pathogen. (A) in March 2017, the diseased citrus trees were checked for possible assessment endophyte before starting experiment; (B) in April 2017, all the trees treated with Fertilizer 1 with Bacillus amyloliquefaciens $Y 2$; The $X$-axis represents endophytes and penicillin injection through trunk (1); endophyte injection (2); Penicillin spray (3); Endophyte spray (4); Penicillin injection (5); Control CK1 and CK2 $(6,7)$; (C) fertilizer 2 with Bacillus amyloliquefaciens Y2; CK2 and CK3 $(6,7)$; (D) no organic fertilizer (F0) was used as control; CK3 and CK1 $(6,7)$ and indigenous endophytes showing number increase of endophytes due to dispersal of endophytes in all the trees even control samples; (E) Endophytes population during different sampling times along with; $(F)$ successive reduction of Clas pathogen inside disease trees using conventional PCR and (G) Nested PCR. The populations of endophytic bacteria were calculated based on average logarithm (base 10) of bacteria recovered from the plant leaves. The log cfu values were analyzed with GraphPad Prism 5 (San Diego, 
CA, USA). The values are the means \pm the standard deviation with statistical significance difference among different treatments with different letters $(P \leq 0.05)$.
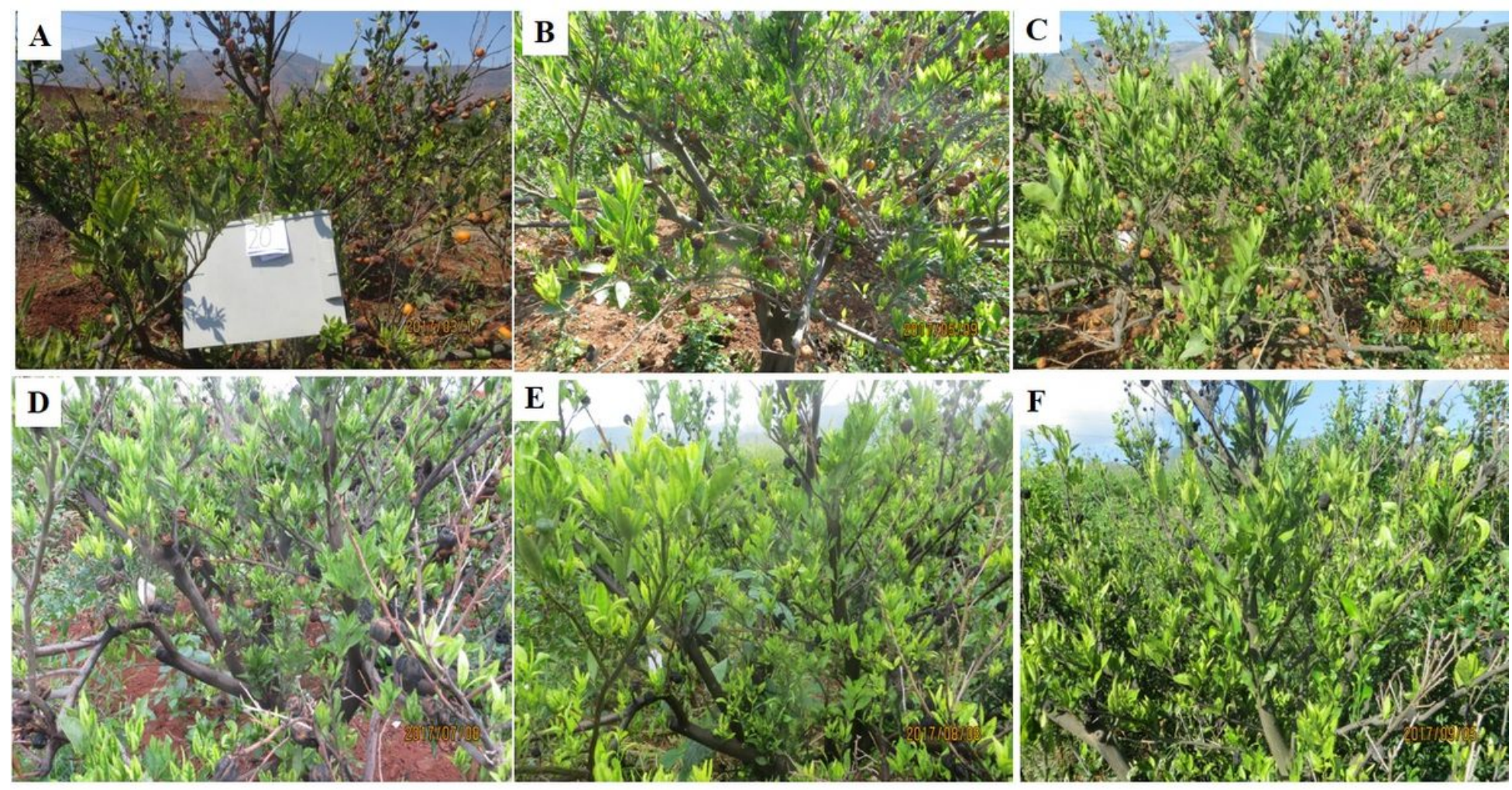

\section{Figure 4}

Management of huanglongbing in the diseased canopy in Binchun county, Yunnan. (A) diseased citrus tree in early March; (B) successful treatment for 2 months with endophytes resulted in the more vigorous citrus growth; (C-F) after 6 months of application with Bacillus subtilis L1-21 in the diseased citrus grove resulted in more than $95 \%$ control effect of the Clas pathogen, trees showed more robust, healthy shooting, and with some of the trees yielding normal fruits. 


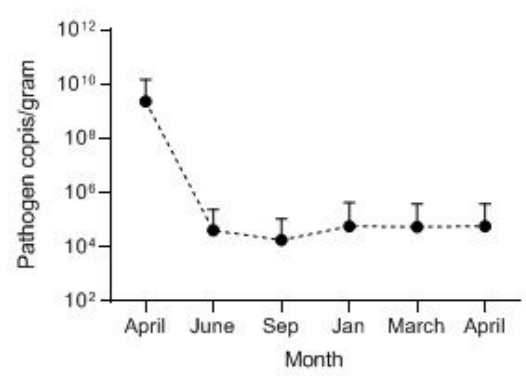

B

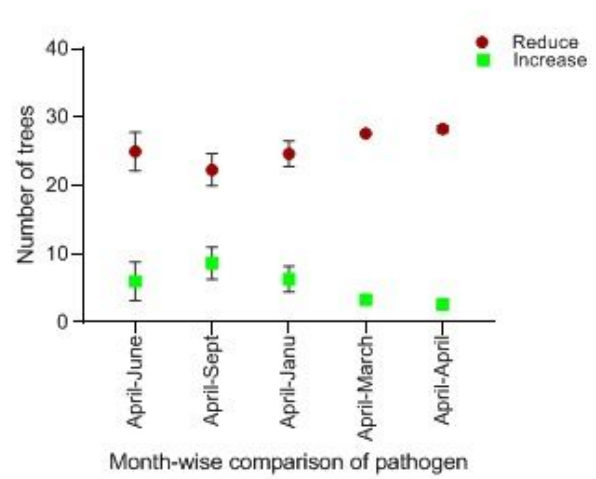

D

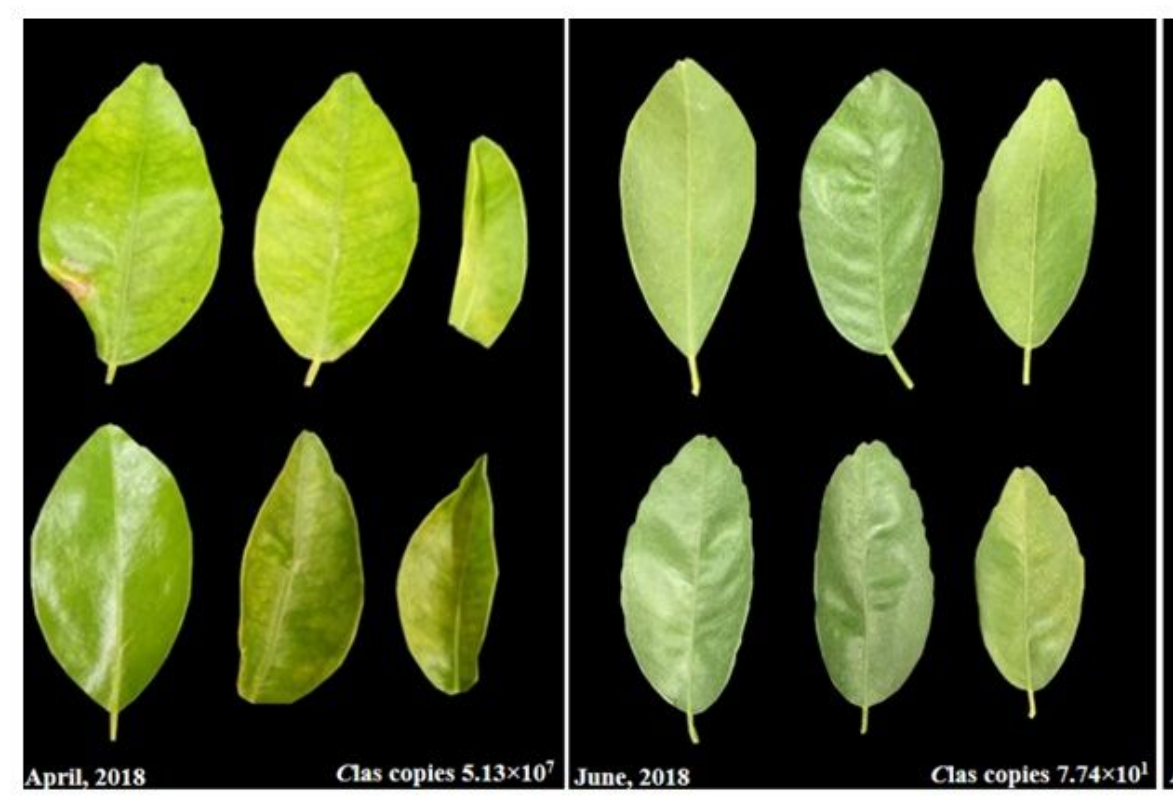

C
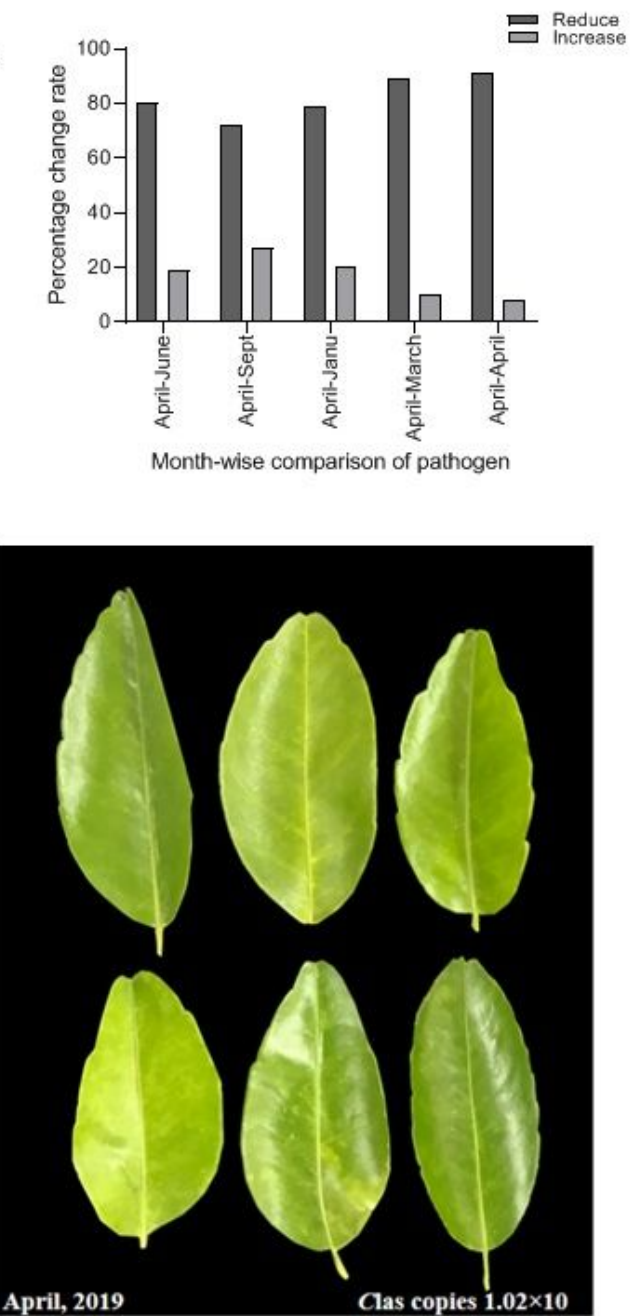

\section{Figure 5}

A total of 93 citrus diseased sampled trees were treated with endophytes and Clas pathogen were monitored throughout the study period from April 2018 to April 2019. (A) CT values obtained through qPCR were changed to pathogen copies per gram of citrus leaf using standard curve generated from pUC18-382 recombinant plasmid; (B) number of citrus trees displayed reduction of Clas pathogen during different time intervals, April-September 2018, and January, March, April 2019. Each repeat contains 31 citrus trees; (C) percentage reduction of pathogen across month-wise indicating reduction of pathogen from time to time; (D) citrus leaves showing yellow symptoms before application of endophytes (April, 2018), to more greenish leaves with the different time intervals decreasing pathogen copies 107 to 10 Clas/gram citrus leaf midribs. 
A

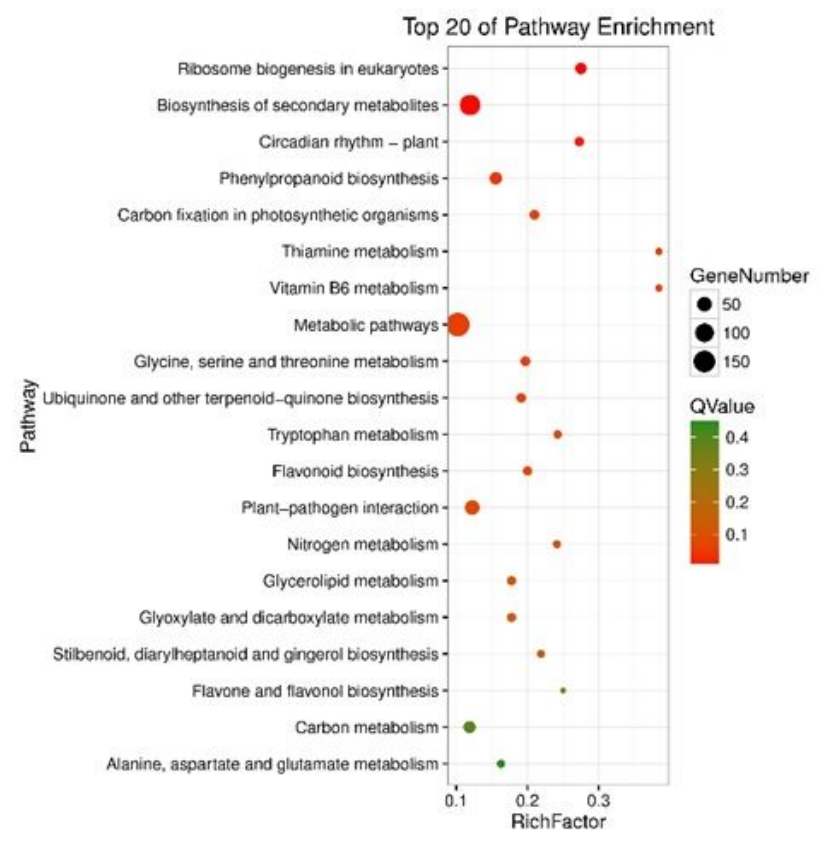

B

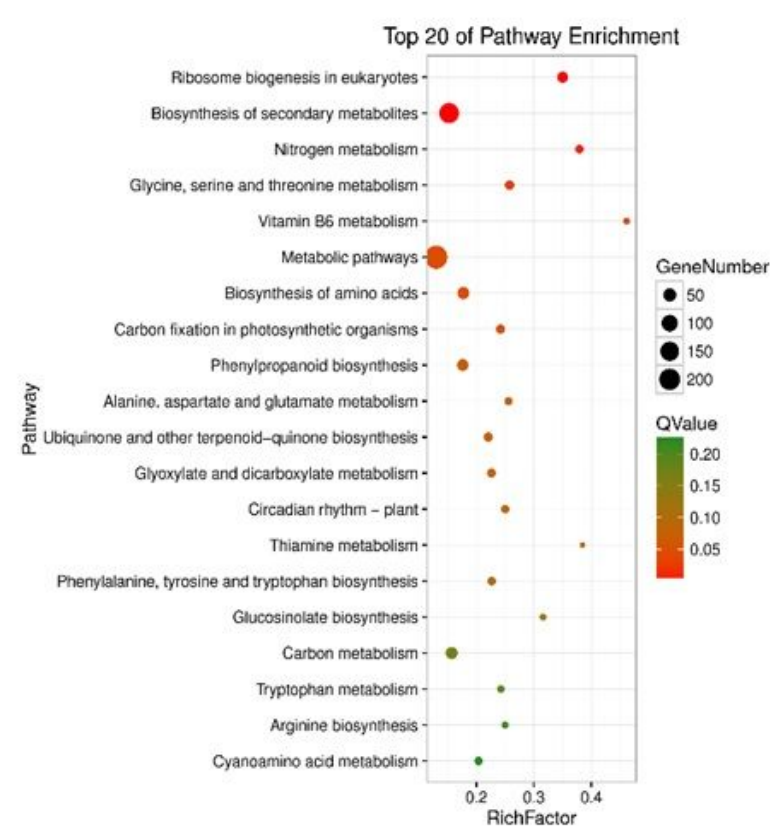

C

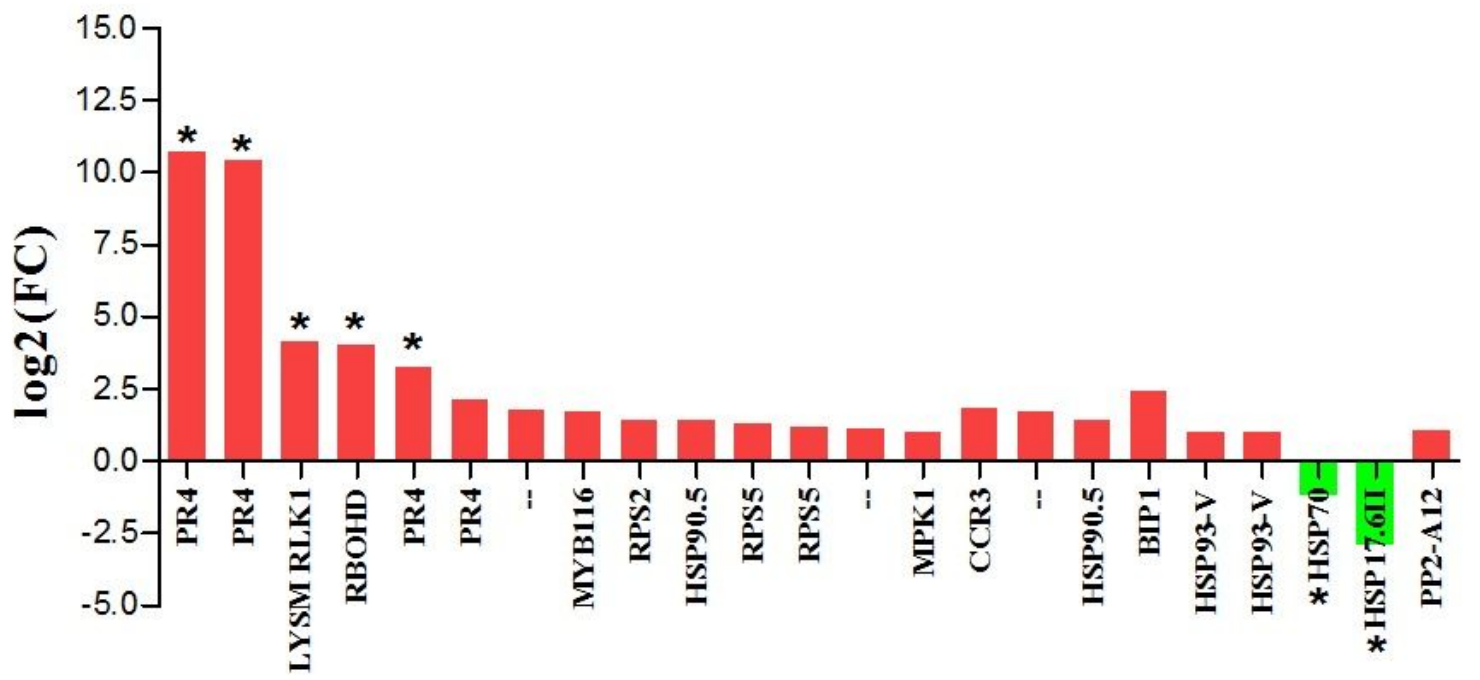

Pathogen resistance genes

\section{Figure 6}

Regulation of important pathways and pathogen resistance genes in response to Bacillus subtilis L1-21. The top $20 \mathrm{KEGG}$ enrichment pathway analysis of differentially expressed genes in the untreated and endophyte treated citrus trees (padj<0.05). (A) Diseased trees treated with endophytes; (B) Healthy trees treated with endophytes; (C) Pathogen resistance genes upregulated in the diseased citrus trees after treated with endophyte L1-21; * corrected p-value $<0.05$. 


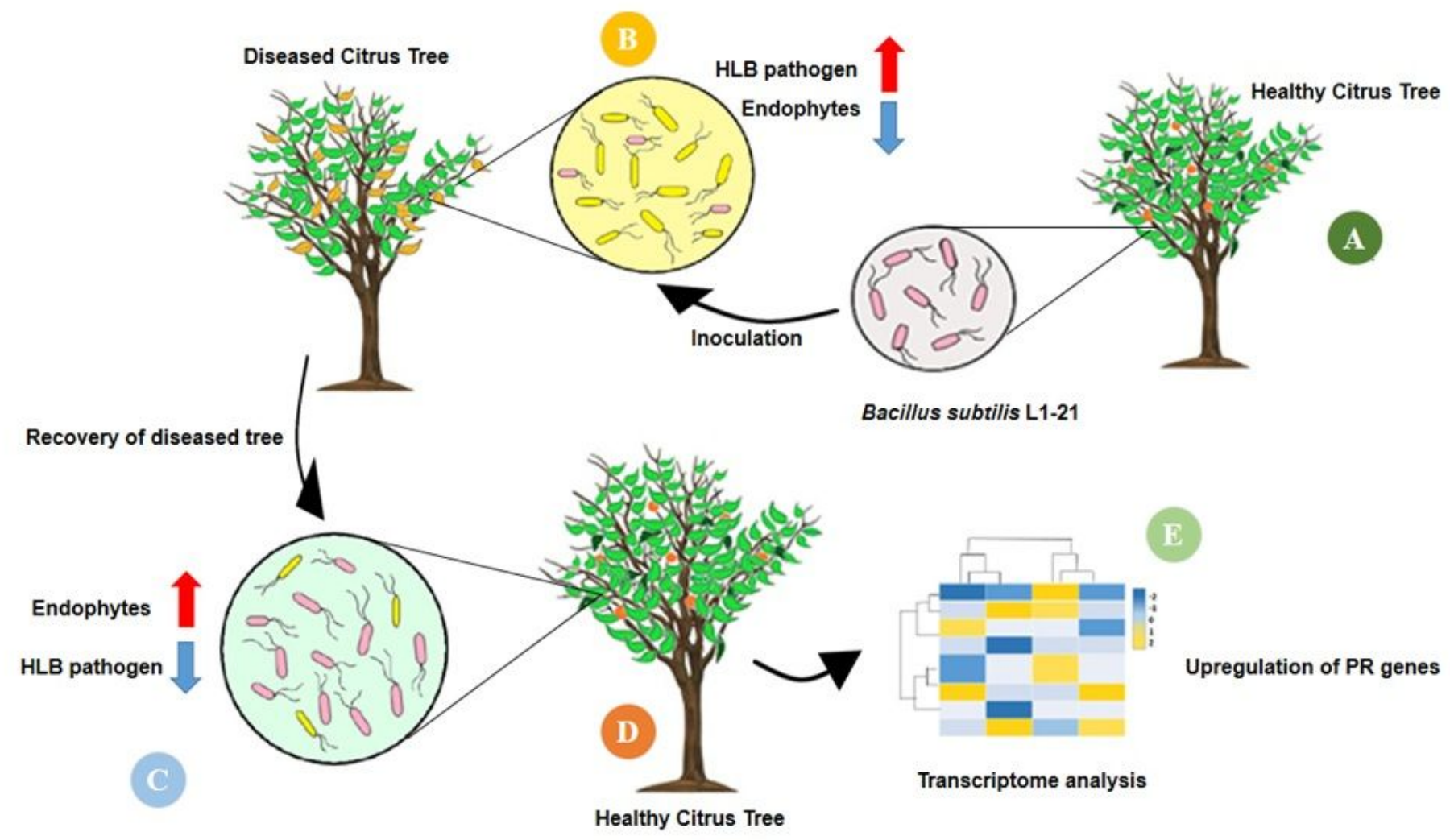

Figure 7

Concluding sketch illustrating the different events taking place in the diseased citrus fields through restructuring bacterial endophytes for management of HLB disease. (A) Indigenous endophyte Bacillus subtilis L1-21, displaying marked pinkish colonies, was isolated from healthy citrus plants; (B) Diseased citrus trees with more pathogen and less endophytes were inoculated with the endophyte B. subtilis L121; (C) Endophyte L1-21 shifted the bacterial endophytic community and exclude/restricted the pathogen colonization in diseased citrus trees from two different regions by regular application for one year; (D) The recovered tree showing more robust leaves and fruits; $(E)$ Pathogen resistance genes were upregulated in diseased citrus host after application of potential endophyte B. subtilis L1-21.

\section{Supplementary Files}

This is a list of supplementary files associated with this preprint. Click to download.

- Metadatatableforalldepositedsequences.txt

- Classupplementary20200924.docx 